\title{
A Brief Overview of Current Drug Repurposing Approaches for COVID-19 Management
}

\author{
Pedro da Fonseca Soares Rodrigues ${ }^{1}$, Douglas Vieira Thomaz ${ }^{2}$ \\ ${ }^{1}$ Kursk State Medical University \\ 3 Karl Marx, Kursk, 305041, Russia \\ ${ }^{2}$ Universidade Federal de Goiás \\ 240 street, Leste Universitário district, Goiânia - G0, 74605-170, Brazil
}

DOI: $10.22178 /$ pos.57-1

LCC Subject Category: RM1-950

Received 10.04.2020

Accepted 29.04.2020

Published online 30.04 .2020

Corresponding Author:

Pedro da Fonseca Soares Rodrigues

pedrodafonseca1992@gmail.com

(C) 2020 The Authors. This article

is licensed under a Creative Commons

Attribution 4.0 License @) (1)

\begin{abstract}
This brief overview is intended to shed light on the current drug repositioning (also called drug repurposing) in the therapeutics of the novel coronavirus disease which emerged in 2019 (COVID-19). In this sense, the repositioning drugs for new indications can offer a better riskversus-reward trade-off when compared to other drug development strategies, given that it makes use of drugs whose safety profile are already understood. Nonetheless, this approach allows healthcare professionals to promptly tackle the disease by investigating readily available drugs against it.
\end{abstract}

Keywords: coronavirus; antiviral; pandemic; outbreak; drug repositioning; healthcare.

\section{COVID-19 outbreak and its current scenario}

On December 31st, 2019, several pneumonia cases linked to a seafood market in Wuhan, China were reported to the World Health Organization (WHO). The fast-spreading infection, now known as coronavirus disease 2019 (COVID-19), is caused by a novel coronavirus (SARS-CoV-2) [1]. This recent global outbreak has raised many concerns regarding the limitations of standard therapeutic protocols against fast-spreading diseases as well as the importance of their epidemiological characteristics. Regarding the severe acute respiratory syndrome, SARS-CoV-2 is the etiological agent of the ongoing pandemic of $2019 \mathrm{CoV}$ disease, which is already responsible for far more deaths than were reported during the previous public health emergencies of international concern provoked by two related pathogenic CoVs from 2002 and 2012 [2].

The cases of infection have been continuously increasing ever since its outbreak. Currently, there are no scientifically reliable approved drugs to treat the infection. In this scenario, there is a need to utilize the existing repertoire of FDA approved drugs to treat the disease [3]. Regard- ing COVID-19 infection, its symptoms are usually flu-like, while non-specific symptoms such as fever, dry cough and malaise are also common, up to the shortness of breath - which is an indicator of bad evolution. In this sense, differential diagnosis plays a crucial role in determining proper patient care, being this goal achieved by point of care immunochromatographic tests, real time polymerase chain reaction (RT-PCR) or by enzyme-linked immunosorbent assay (ELISA) in proper lab environment.

One can find that imaging (CT) could be the answer to the initial assessment of desaturating patients. The bilateral commitment of the lungs together with the epidemiological scenario are clues to the differential diagnosis, despite testing. Such assessment allows differentiation from the single lung disorder seen in Influenza patients. Notwithstanding, the medical personnel should be aware of the potential "cytokine storm" which may be caused also by severe Influenza A [4]. Table 1 showcases the main specific and unspecific symptoms associated to COVID-19. 
Table 1 - Main specific and unspecific symptoms associate to COVID-19

\begin{tabular}{|l|l|}
\hline \multicolumn{2}{|c|}{ Symptoms* } \\
\hline Specific & Unspecific \\
\hline & Fever \\
\hline & Fatigue \\
\hline Shortness of breath\# & Muscle Pain \\
\hline $\begin{array}{l}\text { \# often leads to bilateral lung } \\
\text { commitment }\end{array}$ & Cough \\
\hline & Expectoration \\
\hline & Headache \\
\hline & Hemoptisis \\
\hline & Diarrhea \\
\hline
\end{tabular}

Notes: All symptoms were thoroughly reported by Huang and collaborators in 2020 [5].

\section{Current COVID-19 therapeutics and perspectives on drug repurposing}

Although there is up to date no FDA-approved specific treatment for COVID-19 infection, ex- perimental drugs such as favipiravir and hydroxychloroquine are gaining increasing attention due to their allegedly efficacy. Favipiravir is a pyrazinecarboxamide derivative derivative whose main target is viral RNA-dependent RNA polymerase, while hydroxychloroquine is an aminoquinoline whose pharmacodynamics of its antiviral activity is still unclear. These drugs are selected to undergo investigation following empirical in vitro testing, chemoinformatic or other in silico approaches which correlate their chemical structure to biological activity. These methods are gaining attention due to their low cost when compared to standard medicinal chemistry approaches and provide reliable data under the time constraints imposed by global outbreaks such as COVID-19. In this sense, drug repurposing offers quick insights to employ readily available drugs against unorthodox biological targets $[10,11,12,13]$. Table 2 summarizes the main drugs which are currently under investigation against COVID-19.

Table 2 - Drugs under investigation against COVID-19

\begin{tabular}{|c|c|c|c|c|}
\hline Antiviral drug & $\mathrm{MoA}^{2}$ & Regular indication & FDA-S 4 & References \\
\hline IFN-Alfa ${ }^{1}$ & Miscellaneous & Hepatitis & + & [6] \\
\hline Lopinavir/ritonavir ${ }^{2}$ & Protease Inhibitor & HIV & + & [11] \\
\hline Ribavirin $^{2}$ & Nucleotide analogue & Broad spectrum antiviral & + & [6] \\
\hline Chloroquine phosphate $^{1}$ & Miscellaneous & Antimalarial & + & [10] \\
\hline Arbidol $^{3}$ & Miscellaneous & Influenza & - & [9] \\
\hline Favipiravir ${ }^{2}$ & Nucleotide analogue & Influenza & - & [14] \\
\hline Remdesivir $^{2}$ & Nucleotide analogue & Ebola & - & [12] \\
\hline Darunavir $^{2}$ & Protease Inhibitor & HIV & + & [13] \\
\hline Atazanavir $^{2}$ & Protease Inhibitor & HIV & + & [8] \\
\hline DRACOs $^{35}$ & Suppress viral RNA synthesis & Broad spectrum antiviral & - & [7] \\
\hline Ivermectin $^{1}$ & Miscellaneous & Antiparasitic & + & [15] \\
\hline
\end{tabular}

Notes:

${ }^{1}$ Targets viral replication or entry/apoptosis; ${ }^{2}$ Targets viral replication; ${ }^{3}$ Targets viral entry/apoptosis; MoA Mechanism of Action; ${ }^{4}$ FDA-S - FDA status; ${ }^{5}$ Double-stranded RNA Activated Caspase Oligomerizer.

Among potential drugs, the nucleotide analogue remdesivir is shown to be one of the most promising and hopeful anti-viral in therapeutic. It works by targeting viral RNA-dependent RNA polymerase (RdRp) while evading proofreading by viral exoribonuclease [16], resulting in premature termination of viral RNA transcription. Unlike other nucleotide analogues, remdesivir is a phosphoramidate prodrug with broadspectrum activity against many virus families, including Orthocoronavirinae, in which the pathogenic SARS-CoV and Middle East respiratory syndrome coronavirus are included $[17,18]$.

The other nucleotide analogue, RdRp inhibitor favipiravir is easily recognized as a substrate of viral RNA polymerase in many RNA viruses [19]. Recently, preliminary results of clinical studies have shown favipiravir to have good potency in treatment of Chinese patients with COVID infection [18]. Favipiravir was approved for the treatment of COVID-19 in China in March, 2020. In addition, patients with COVID-19 infection are 
being recruited for randomized trials to evaluate the efficacy of favipiravir plus interferon- $\alpha$ (ChiCTR2000029600) and favipiravir plus baloxavir marboxil (ChiCTR2000029544) [20].

Protease inhibitors (PIs) are important antiviral drug agents. In the Orthocoronavirinae context, the targets of PIs are papain-like protease and 3C-like protease [21]. It is noteworthy to mention that [22] compared the efficacy of prophylactic remdesivir as well as therapeutic remdesivir with that of LPV/ritonavir - IFNb combination therapy in a humanized MERS-CoV infection model. They observed the efficacy of remdesivir was superior to that of LPV/RTV-IFNb against MERS-CoV in terms of viral load reduction and improvement in extent of pathologic change in lung tissue [22]. Chinese Clinical Trial Register number, ChiCTR2000029308 failed based on the usage of LPV/RTN to provide benefits compared to standard care alone, hence there was no difference in the reduction of viral RNA loading for severe SARS-CoV-2 patients [23].

Chloroquine was shown to increase endosomal $\mathrm{pH}$, which prevents virus/cell fusion. It also interferes with the glycosylation of cellular receptors of SARS-CoV. Although the in vitro data of chloroquine is promising (EC90 of $6.90 \mu \mathrm{M}$, using Vero E6 cells infected by SARS-CoV-2), an extensive prescription of chloroquine in clinical treatment of SARS-CoV-2 is a completely off-label use [24].

Originally identified as an inhibitor of the interaction between the human immunodeficiency virus-1 (HIV-1) integrase protein (IN) and the importin (IMP) $\alpha / \beta 1$ heterodimer responsible for IN nuclear import [25], Ivermectin is an FDAapproved broad spectrum antiparasitic agent that has since been confirmed to inhibit IN nuclear import and HIV-1 replication. Other actions of ivermectin have been reported, but ivermectin has been shown to inhibit nuclear import of host and viral proteins, including dengue virus (DENV) non-structural protein 5 [26].

The Oswaldo Cruz Foundation (Fiocruz) said in a note that it found in research on treatments for COVID-19 that the drug Atazanavir, used to treat HIV, was able to inhibit viral replication, in addition to reducing the production of proteins that are linked to the inflammatory process in the lungs and, therefore, to the worsening of the patients' clinical condition [27].

Considering the lengthy process of approving novel drugs to general health practice, the repurposing of preexistent medicines is surely a less strenuous approach in the path towards prompt medical treatment. In this sense, the commercialization of novel compounds in pharmaceutical formulations is preceded by thorough evaluation of their efficacy and safety profiles through several approaches such as in silico, in vitro, ex vivo and finally in vivo investigations. This process may take about ten years to achieve completion [28], while drug repurposing follows mainly clinical trials to attest the usefulness of the proposed treatment under the light of patient safety. Considering that emerging global outbreaks such as COVID-19 require fast and efficient intervention to counter mass contamination, drug repurposing is a remarkable alternative to tackle the epidemy in its beginning.

This has been a way out for several diseases, for instance, Brazilian researchers are working with derivatives of triazoles, known antifungals, for the treatment of sickle cell anemia. For neglected diseases, the repositioning of drugs is an excellent strategy, in which little is invested, or even in emergency diseases, such as the current COVID19 outbreak $[29,30]$.

\section{CONCLUSION}

The repositioning drugs for new indications can offer a better risk-versus-reward trade-off when compared to other drug development strategies, given that it makes use of drugs whose safety profile are already understood. Nonetheless, this approach allows healthcare professionals to promptly tackle the disease by investigating readily available drugs against it. However, care must be taken and all clinical investigations must be performed in order to ensure the efficacy of the treatment under the light of patient safety.

\section{CONFLICT OF INTEREST}

Authors declare no conflict of interest. 


\section{REFERENCES}

1. World Health Organization. (2020, January 5). Pneumonia of unknown cause - China. Retrieved from https://www.who.int/csr/don/05-january-2020-pneumonia-of-unkown-cause-china/en/

2. Fintelman-Rodrigues, N., Sacramento, C. Q., Lima, C. R., da Silva, F. S., Ferreira, A. C., Mattos, M., ... Souza, T. M. L. (2020). Atazanavir inhibits SARS-CoV-2 replication and pro-inflammatory cytokine production. doi: 10.1101/2020.04.04.020925

3. Arya, R., Das, A., Prashar, V., \& Kumar, M. (2020). Potential inhibitors against papain-like protease of novel coronavirus (SARS-CoV-2) from FDA approved drugs. doi: 10.26434/chemrxiv.11860011.v2

4. Liu, Q., Zhou, Y., \& Yang, Z. (2015). The cytokine storm of severe influenza and development of immunomodulatory therapy. Cellular \& Molecular Immunology, 13(1), 3-10. doi: 10.1038/cmi.2015.74

5. Huang, C., Wang, Y., Li, X., Ren, L., Zhao, J., Hu, Y., ... Cao, B. (2020). Clinical features of patients infected with 2019 novel coronavirus in Wuhan, China. The Lancet, 395(10223), 497-506. doi: 10.1016/s0140-6736(20)30183-5

6. Morgenstern, B., Michaelis, M., Baer, P. C., Doerr, H. W., \& Cinatl, J. (2005). Ribavirin and interferon- $\beta$ synergistically inhibit SARS-associated coronavirus replication in animal and human cell lines. Biochemical and Biophysical Research Communications, 326(4), 905-908. doi: 10.1016/j.bbrc.2004.11.128

7. Rider, T. H., Zook, C. E., Boettcher, T. L., Wick, S. T., Pancoast, J. S., \& Zusman, B. D. (2011). BroadSpectrum Antiviral Therapeutics. PLoS ONE, 6(7), e22572. doi: 10.1371/journal.pone.0022572

8. Vinicius, L. (2020, April 8). HIV antiretroviral drug studied to fight COVID-19. The medicine may inhibit the replication of the virus. Retrieved from https://agenciabrasil.ebc.com.br/en/saude/noticia/2020-04/hiv-antiretroviral-drug-studiedfight-covid-19

9. Leneva, I. A., Russell, R. J., Boriskin, Y. S., \& Hay, A. J. (2009). Characteristics of arbidol-resistant mutants of influenza virus: Implications for the mechanism of anti-influenza action of arbidol. Antiviral Research, 81(2), 132-140. doi: 10.1016/j.antiviral.2008.10.009

10. Singh, A. K., Singh, A., Shaikh, A., Singh, R., \& Misra, A. (2020). Chloroquine and hydroxychloroquine in the treatment of COVID-19 with or without diabetes: A systematic search and a narrative review with a special reference to India and other developing countries. Diabetes \& Metabolic Syndrome: Clinical Research \& Reviews, 14(3), 241-246. doi: 10.1016/j.dsx.2020.03.011

11. Su, B., Wang, Y., Zhou, R., Jiang, T., Zhang, H., Li, Z., ... Sun, L. (2019). Efficacy and Tolerability of Lopinavir/Ritonavir- and Efavirenz-Based Initial Antiretroviral Therapy in HIV-1-Infected Patients in a Tertiary Care Hospital in Beijing, China. Frontiers in Pharmacology, 10. doi: 10.3389/fphar.2019.01472

12. Wang, M., Cao, R., Zhang, L., Yang, X., Liu, J., Xu, M., ... Xiao, G. (2020). Remdesivir and chloroquine effectively inhibit the recently emerged novel coronavirus (2019-nCoV) in vitro. Cell Research, 30(3), 269-271. doi: 10.1038/s41422-020-0282-0

13. Sd.News. (2020, February 5). Abidol and darunavir can effectively inhibit coronavirus. Retrieved from http://www.sd.chinanews.com/2/2020/0205/70145.html (in Chinese).

14. Chen, C., Zhang, Y., Huang, J., Yin, P., Cheng, Z., Wu, J., ... Wang, X. (2020). Favipiravir versus Arbidol for COVID-19: A Randomized Clinical Trial. doi: 10.1101/2020.03.17.20037432

15. Caly, L., Druce, J. D., Catton, M. G., Jans, D. A., \& Wagstaff, K. M. (2020). The FDA-approved drug ivermectin inhibits the replication of SARS-CoV-2 in vitro. Antiviral Research, 178, 104787. doi: 10.1016/j.antiviral.2020.104787 
16. Agostini, M. L., Andres, E. L., Sims, A. C., Graham, R. L., Sheahan, T. P., Lu, X., ... Denison, M. R. (2018). Coronavirus Susceptibility to the Antiviral Remdesivir (GS-5734) Is Mediated by the Viral Polymerase and the Proofreading Exoribonuclease. mBio, 9(2). doi: 10.1128/mbio.00221-18

17. Shen, L., Niu, J., Wang, C., Huang, B., Wang, W., Zhu, N., ... Tan, W. (2019). High-Throughput Screening and Identification of Potent Broad-Spectrum Inhibitors of Coronaviruses. Journal of Virology, 93(12). doi: 10.1128/jvi.00023-19

18. Jean, S.-S., Lee, P.-I., \& Hsueh, P.-R. (2020). Treatment options for COVID-19: The reality and challenges. Journal of Microbiology, Immunology and Infection. doi: 10.1016/j.jmii.2020.03.034

19. Furuta, Y., Komeno, T., \& Nakamura, T. (2017). Favipiravir (T-705), a broad spectrum inhibitor of viral RNA polymerase. Proceedings of the Japan Academy, Series B, 93(7), 449-463. doi: 10.2183/pjab.93.027

20. Jean, S.-S., Lee, P.-I., \& Hsueh, P.-R. (2020). Treatment options for COVID-19: The reality and challenges. Journal of Microbiology, Immunology and Infection. doi: 10.1016/j.jmii.2020.03.034

21. Zumla, A., Chan, J. F. W., Azhar, E. I., Hui, D. S. C., \& Yuen, K.-Y. (2016). Coronaviruses - drug discovery and therapeutic options. Nature Reviews Drug Discovery, 15(5), 327-347. doi: $10.1038 / \mathrm{nrd} .2015 .37$

22. Sheahan, T. P., Sims, A. C., Leist, S. R., Schäfer, A., Won, J., Brown, A. J., ... Baric, R. S. (2020). Comparative therapeutic efficacy of remdesivir and combination lopinavir, ritonavir, and interferon beta against MERS-CoV. Nature Communications, 11(1). doi: 10.1038/s41467-01913940-6

23. Cao, B., Wang, Y., Wen, D., Liu, W., Wang, J., Fan, G., ... Wei, M. (2020). A Trial of Lopinavir-Ritonavir in Adults Hospitalized with Severe Covid-19. New England Journal of Medicine, 382(19), 17871799. doi: 10.1056/nejmoa2001282

24. Cortegiani, A., Ingoglia, G., Ippolito, M., Giarratano, A., \& Einav, S. (2020). A systematic review on the efficacy and safety of chloroquine for the treatment of COVID-19. Journal of Critical Care. doi: 10.1016/j.jcrc.2020.03.005

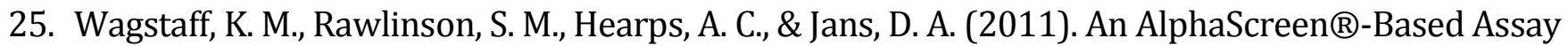
for High-Throughput Screening for Specific Inhibitors of Nuclear Import. Journal of Biomolecular Screening, 16(2), 192-200. doi: 10.1177/1087057110390360

26. Wagstaff, K. M., Sivakumaran, H., Heaton, S. M., Harrich, D., \& Jans, D. A. (2012). Ivermectin is a specific inhibitor of importin $\alpha / \beta$-mediated nuclear import able to inhibit replication of HIV-1 and dengue virus. Biochemical Journal, 443(3), 851-856. doi: 10.1042/bj20120150

27. Rosas, R. (2020, April 6). Coronavírus: Testes da Fiocruz indicam que atazanavir foi capaz de inibir replicação de vírus. Retrieved from https://valorinveste.globo.com/mercados/brasil-epolitica/noticia/2020/04/06/coronavirus-testes-da-fiocruz-indicam-que-atazanavir-foi-capazde-inibir-replicacao-de-virus.ghtml

28. Romanelli, M. M., Costa-Silva, T. A. da, Cunha-Junior, E., Dias Ferreira, D., Guerra, J. M., Galisteo, A. J., ... Tempone, A. G. (2019). Sertraline Delivered in Phosphatidylserine Liposomes Is Effective in an Experimental Model of Visceral Leishmaniasis. Frontiers in Cellular and Infection Microbiology, 9. doi: $10.3389 /$ fcimb.2019.00353

29. Sciani, J. M., \& de Lima, L. P. (2020, April 7). Reposicionamento de fármacos. O caso da cloroquina e o COVID-19. Retrieved from https://www.inovamol.com.br/post/reposicionamento-de-fármacos

30. Ashburn, T. T., \& Thor, K. B. (2004). Drug repositioning: identifying and developing new uses for existing drugs. Nature Reviews Drug Discovery, 3(8), 673-683. doi: 10.1038/nrd1468 